\title{
Método prático e eficiente para estimar a área foliar de gramíneas forrageiras tropicais
}

\author{
Sousa, L.F. ${ }^{1}$; Santos, J.G.D. ' ; Alexandrino, E. ' ; Maurício, R.M. ${ }^{2}$; Martins, A.D. ${ }^{1}$ e Sousa, J.T.L. ${ }^{1}$
}

'Universidade Federal do Tocantins. Campus Universitário de Araguaína. Brasil.

2Universidade Federal de São João del Rei. Campus Universitário de São João del Rei. Brasil.

\section{PALAVRAS CHAVE ADICIONAIS}

Estrutura do pasto

Fisiologia vegetal.

Forragicultura.

Metodologias.

Pastagens.

\section{RESUMO}

O método aqui proposto, denomidado de Área Foliar - Universidade Federal do Tocantins (AFUFT) baseia-se em três medidas da folha (comprimento total, largura na base do limbo e largura no meio do limbo), decompondo-a em um triângulo e um trapézio para o calculo da AF. O AFUFT (método II) foi comparado com três métodos: método I - indireto, com uso de aparelho de interceptação luminosa (SunScan®); método III - segmenta as folhas em partes de $10 \mathrm{~cm}$, seguido de medida da largura destes segmentos; método IV - utiliza-se scanners e programa computacional (aqui considerado como método padrão). As quatro metodologias foram testadas em blocos casualisados, sendo os blocos as 24 parcelas 14,0 $\mathrm{m} \times 1,0 \mathrm{~m}$ ) de Urochloa brizantha cv. 'Marandu'. O método AFUFT apresentou os maiores coeficientes de correlação $(r=0,99 ; p<0,05)$ com o método padrão. Já o método I superestimou a $\mathrm{AF}$ e o índice de área foliar e o método III subestimou estas variáveis. Para estimativas de área foliar de gramínea forrageira, o método aqui apresentado é uma ferramenta promissora, prática e ágil, em relação aos demais métodos estudados.

\section{Practical and efficient method to estimate leaf area index in tropical forage grasses}

\section{SUMMARY}

The method here proposed, nominated of leaf area - Federal University of Tocantins (AFUFT) fill out these flaws and bases on three measures of the leaf (total length, leaf blade base width and leaf blade middle width), decomposing it in a triangle and a trapeze for calculate of LA. AFUFT (method II) was compared with three methods: method I - indirect, with use of apparel of luminous interception (SunScan $®$ ); method III - direct, segmented the leaf in parts of $10 \mathrm{~cm}$, followed by measure of segments blade middle width; method IV - direct, used scanners and computer software (here considered as standard method). The four methodologies were set up in a randomized block design, being the blocks the 24 stonemasons $(4.0 \mathrm{~m} \times 1.0 \mathrm{~m})$ of Urochloa brizantha cv. 'Marandu'. The AFUFT presented the largest correlation coefficients $(r=0.99 ; p<0.05)$ with the standard method. The method I overestimated LA and LAI and the method III underestimated these variables. For obtaining the leaf area of tropical grasses, the method here presented is an promising, practice and agile tool, in relation to the other studied methods.

\section{INFORMACIÓN}

Cronología del artículo.

Recibido/Received: 23.5.2014

Aceptado/Accepted: 1.12.2014

On-line: 16.3 .2015

Correspondencia a los autores/Contact e-mail:

luciano.sousa@uft.edu.br.

\section{INTRODUÇÃO}

Atributos estruturais como o índice de área foliar (IAF) e a densidade populacional de perfilhos, merecem destaque nos estudos com gramíneas forrageiras. Estes atributos estão intimamente ligados à produção de biomassa e a distribuição destes componentes tem influência direta sobre o consumo de matéria seca pelos bovinos (Fagundes et al., 2005).

Atualmente, o IAF tem sido utilizado com sucesso como parâmetro indicador do momento de entrada e retirada dos animais do pasto. Isto permite um melhor controle sobre a quantidade de limbo foliar, tanto disponível para o consumo, quanto residual para a adequada rebrota e recomposição do dossel forrageiro (Difante et al., 2011). Diversos métodos têm sido empregados na estimativa da área foliar (AF), os quais se dividem em métodos diretos e indiretos. Como exemplo de métodos diretos, cita-se o uso de scanner, a fragmentação e mensuração de segmentos de lâminas foliares, dentre outros. Estes métodos apresentam como principais falhas e dificuldades a perda de tecido foliar, durante a segmentação, a lentidão no processa- 
Tabela I. Área foliar e índice de área foliar (IAF) referentes aos quatro métodos estudados (Leaf area and leaf area index (LAl) for the four studied methods).

\begin{tabular}{lccccc}
\hline Métodos & $\mathrm{I}-\mathrm{IAF} 1$ & $\mathrm{II}(\mathrm{AFUFT})-\mathrm{IAF}$ & $\mathrm{III}-\mathrm{IAF}$ & $\mathrm{IV}-$ IAF & $\mathrm{CV}$ \\
\hline $\mathrm{AF}^{1}$ & $35902^{\mathrm{a}}$ & $33169^{\mathrm{b}}$ & $31723^{\mathrm{c}}$ & $32938^{\mathrm{b}}$ & 3,84 \\
$\mathrm{IAF}^{2}$ & $3,59^{\mathrm{a}}$ & $3,32^{\mathrm{b}}$ & $3,17^{\mathrm{c}}$ & $3,29^{\mathrm{b}}$ & 3,37 \\
\hline
\end{tabular}

$\overline{\mathrm{AF}}=$ Área foliar $\left(\mathrm{cm}^{2}\right.$ de limbo foliar); IAF= Índice de área foliar $\left(\mathrm{cm}^{2}\right.$ de limbo foliar por $\mathrm{cm}^{2}$ de solo); Médias seguidas por letras diferentes na linha diferem a $5 \%$ de probabilidade de erro tipo I pelo teste de Tukey; CV= Coeficiente de variação em percentagem.

O IAF é calculado pela divisão da área do limbo das folhas (expressão $\mathrm{cm}^{2}$ ) de todas plantas forrageiras em uma área de $10000 \mathrm{~cm}{ }^{2}$ de solo de pastagens ocupado com a forrageira em questão $\left(\mathrm{cm}^{2} / \mathrm{cm}^{2}\right)$.

mento das amostras, além do alto custo dos scanners. Já os métodos indiretos empregam equipamentos específicos, os quais medem a interceptação luminosa e estimam a AF indiretamente, a exemplo dos aparelhos LI-COR modelo LAI-2000 e o SunScan ${ }^{\circledR}$-Delta-T. Neste tipo de avaliação indireta, são considerados, na obtenção da AF e do IAF, os tecidos vivos, senescentes e mortos e não somente folhas fotossinteticamente ativas (Bréda, 2003).

Com intuito de minimizar erros e desvantagens operacionais, na estimativa da AF, o objetivo com este estudo é testar a viabilidade de uma metodologia simples e prática para quantificar esta variável.

\section{MATERIAL E MÉTODOS}

O clima da região (latitude $07^{\circ} 13^{\prime} 40^{\prime \prime} \mathrm{S}$ e longitude $48^{\circ} 14^{\prime} 25^{\prime \prime}$ W), segundo classificação Köppen, é AW - Tropical de verão úmido e período de estiagem no inverno. $\mathrm{O}$ delineamento experimental foi em blocos casualisados, sendo os tratamentos as quatro metodologias e os blocos as 24 parcelas $(4,0 \mathrm{~m} \times 1,0 \mathrm{~m})$ cultivadas com $U$. brizantha 'Marandu'. As variáveis analisadas foram a AF e o IAF.

No método I, utilizou-se um aparelho SunScan ${ }^{\circledR}$, o qual mede a interceptação luminosa acima do dossel e ao nível do solo para estimar a área AF e o IAF automaticamente. Após a aplicação do método I, coletou-se amostras em cada parcela com auxílio de um quadrado de metal (área de 0,25 $\mathrm{m}^{2}$ ) e corte das plantas a $5 \mathrm{~cm}$ acima do solo. Em laboratório, determonou-se a massa do material recém colhido e a separação manual do material vivo e morto. $\mathrm{O}$ material vivo foi fraciondo em lãminas foliares e hastes/bainha e posteriormente pesado. Em seguida uma sub-amostra de aproximadamente $30 \mathrm{~g}$ de lâmina foliar foi utilizada para obtenção da AF e IAF por métodos diretos. O método II, denominado AFUFT, baseia-se em três medidas de todas as lâminas da sub-amostra (comprimento total - Med- $A$, largura da base do limbo - Med- $B$, e largura no meio do limbo - Med-C), obtidas com régua milimetrada (figura 1). $A F=$ Área do triângulo $\left[(\text { Med-C })^{*}(\right.$ Med-A/2) $\left.) / 2\right]+a$
Área do trapézio [((Med-C+Med-B)/2)*(Med-A/2)]. As sub-amostras utilizadas no método II foram utilizadas no método III, o qual é o mais rotineiramente empregado em estudos com forrageiras sob pastejo (Sbrissia e Silva, 2008). Este método não concidera, na avaliação, seguimentos menores que $10 \mathrm{~cm}$. No método IV, considerado aqui como padrão, os seguimentos foliares utilizados no método III, incluindo os menores que 10 $\mathrm{cm}$, foram escanados (scanner de mesa - modelo Canon Lide 110). Em seguida as imagens (300 pixels) foram processadas pelo programa Image ${ }^{\circledR}$ para obtenção das áreas dos segmentos e consequentemente das áreas foliares. A área foliar, obtida pelos métodos II, III e IV, foi utilizada para o calculo do IAF, com base no peso das lâminas foliares verdes para a área do quadrado $\left(0,25 \mathrm{~m}^{2}\right)$ e peso seco de $30 \mathrm{~g}$ de lâminas foliares verdes de cada amostra coletada. Os métodos foram avaliados por correlação de Pearson, análise de variância e teste de Tukey a $5 \%$.

\section{RESULTADOS E DISCUSSÃO}

Ao estimar AF e o IAF, apenas o método II foi equivalente ao método considerado padrão e de elevada precisão (metodo IV), para os demais houve superestimativa (método I) ou subestimativa (método III) destas variáveis (tabela I). Estes resultados ressaltam a vantagem operacional do método AFUFT, pois pode ser facilmente empregado ao dispensar o uso de aparelhos que utilizam leitores óticos (scanners) e programas computacionais complexos. Além da agilidade na execução, em relação ao método III. Ao estimar a área foliar das gramíneas U. brizantha cv. 'Xaraés' e Panicum maximum cv. 'Massai', através das medidas do comprimento e largura média máxima das folhas, (Silva et al., 2013) encontraram equações lineares com altos coeficientes de determinação estes autores concluíram que tais medidas são adequadas para se estimar a área foliar de gramíneas forrageiras tropicais, em comparação à área foliar real obtida pelo integrador Li-Cor ${ }^{\circledR}$ - modelo LI 3000. A largura média da folha e o comprimento foliar são as medidas que mais contribuem para melhorar a precisão da aquisição da área foliar via

Med-A = Comprimento total do limbo foliar
Med-B = Largura da base do limbo foliar

Med-C = Largura do meio do limbo foliar

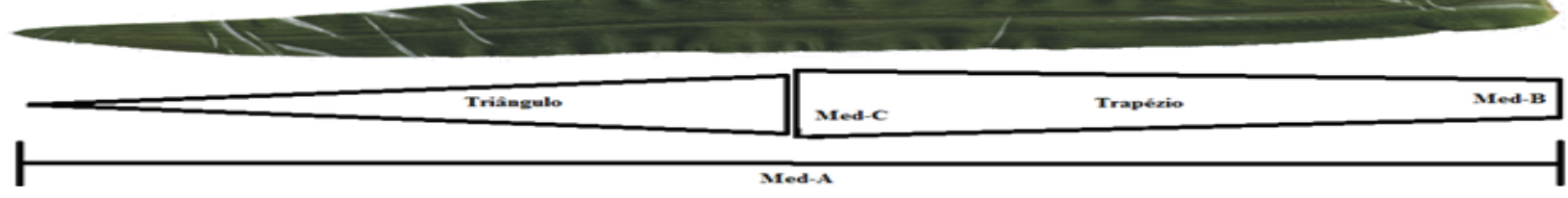

Figura 1. Método II - AFUFT (Method II -AFUFT). 
Tabela II. Coeficientes de correlação entre os resultados de área foliar dos quatro métodos estudados (Correlation coefficients between the results of leaf area of the four methods studied).

\begin{tabular}{llccc}
\hline Métodos & $\mathrm{I}-\mathrm{AF}^{1}$ & II $($ AFUFT) - AF & III - AF & IV - AF \\
\hline I - AF & 1,00 & - & - & - \\
II (AFUFT) - AF & $0,91^{* * * *}$ & 1,00 & - & - \\
III - AF & $0,87^{* * *}$ & $0,89^{* * *}$ & 1,00 & - \\
IV - AF & $0,90^{* * *}$ & $0,99^{* * *}$ & $0,88^{* * *}$ & 1,00 \\
\hline
\end{tabular}

${ }^{* * *} p<0,0001 .(A F)=$ área foliar.

Tabela III. Coeficientes de correlação entre os resultados de IAF dos quatro métodos estudados (Correlation coefficients between the results of the four methods studied IAF).

\begin{tabular}{lcccc}
\hline Métodos & $\mathrm{I}_{-}$IAF $^{1}$ & II (AFUFT) - IAF & III - IAF & IV - IAF \\
\hline I - IAF & 1,00 & - & - & - \\
\hline II (AFUFT) - AF & $0,90^{*+*}$ & 1,00 & - & - \\
III - IAF & $0,88^{*+*}$ & $0,89^{+* * *}$ & 1,00 & - \\
IV - IAF & $0,89^{*+*}$ & $0,98^{*+*}$ & $0,87^{*+*}$ & 1,00 \\
\hline
\end{tabular}

${ }^{* * *} \mathrm{p}<0,0001 .(\mathrm{IAF})=$ área foliar.

mensurações foliares (Silva et al., 2013). Ainda segundo (Silva et al., 2013), as medidas de AF obtidas com régua graduada se equivalem em tempo à utilização do aparelho integrador Li-Cor® - modelo LI 3000.

Dentre os métodos estudados, o AFUFT apresentou maior proximidade com a metodologia padrão, com coeficiente de correlação de 0,99 para a AF e 0,98 para o IAF (tabelas II e III). Isto evidência uma maior acurácea do AFUT, em relação aos métodos I e II, contudo, ressalta-se que estes também apresentaram correlação significativa $(p>0,05)$. A alta correlação entre o método AFUFT e o método padrão pode estar associada a não segmentação do material e auxência de perdas das extremidades, a exemplo do verificado no método III. Também, a simetria bilateral das folhas da U. brizantha é compatível com a decomposição em um triângulo e um trapézio (figura 1). Além disso, o comprimento e a largura média das lâminas foliares são as medidas que mais contribuem para a precisão na aquisição da área foliar real (Silva et al., 2013), aqui bem explorado pelo método AFUFT. O método I (indireto), também tem sido empregado com praticidade, é não destrutivo e permite a estimativa em loco da cobertura do dossel forrageiro. No entanto, imprecisões têm sido verificadas associadas ao tipo de manejo do pasto (Sbrissia e Silva, 2008) e ao efeito climático sobre a deposição sazonal de material senescente (Bréda, 2003), além do considerável custo do equipamento.

\section{CONCLUSÕES}

O método AFUFT é uma ferramenta promissora eficiente, prática e ágil e têm precisão equivalente ao método condiderado padrão para a estimar a área foliar e, consequentemente, para o índice de área foliar. Enquanto há superestimativa destes índices pela leitura com o aparelho SunScan ${ }^{\circledR}$ (método I) e subestimativa pelo método de separação de segmentos (método III).

\section{BIBLIOGRAFIA}

Bréda, N.J.J. 2003. Ground-based measurements of leaf area index: a review of methods, instruments and current controversies. J Exp Bot, 54: 2403-2417.

Difante, G.S.; Nascimento Junior, D.; Silva, S.C.; Euclides, V.P.B.; Montagner, D.B.; Silveira, M.C.T. e Pena, K.S. 201 1. Características morfológicas e estruturais do capim-marandu submetido a combinações de alturas e intervalos de corte. Rev Bras Zootecn, 40: 955-963.

Fagundes, L.J., Fonseca, M.D; Misturas, C.; Morais, R.V.; Vitor, C.M.T; Reis, G.C.; Casagrande, D.R. e Santos, M.E.R. 2005. Índice de área foliar, densidade de perfilhos e acúmulo de forragem em pastagem de capim-braquiária adubada com nitrogênio. Bol Ind Anim, 62: 125-133.

Sbrissia, A.F. e Silva, S.C. da. 2008. Comparação de três métodos para estimativa do índice de área foliar em pastos de capim-marandu sob lotação contínua. $R$ Bras Zootecn, 37: 212-220.

Silva, W.L.; Costa, J.P.R; Caputti, G.P.; Galzerano, L. e Ruggieri, A.L. 2013. Medidas lineares do limbo foliar dos capins Xaraés e Massai para a estimativa da área foliar. Rev Biot, 26: 11-18. 
